\title{
The Effects of Therapeutic Exercise With and Without Mobilization in Participants With Chronic Ankle Instability: A Randomized Controlled Trial
}

\author{
Cameron Bolton, Sheri Hale, and Todd Telemeco
}

\begin{abstract}
Context: Manual therapy (MT) is reported to increase range of motion (ROM), improve balance, and decrease pain in individuals with chronic ankle instability (CAI). Additional literature is needed to examine the effectiveness of the addition of MT to a therapeutic exercise regimen in individuals with CAI. Objective: To examine the combined effects of thrust joint manipulation (TJM) and exercise on function in participants reporting CAI. Design: Randomized controlled trial. Setting: Research laboratory. Participants: A convenience sample of 30 participants (mean age 23.7 [3.65] y; mean height 169.50 [9.50] cm; mean mass 66.48 [10.64] kg). Intervention: Participants were randomly allocated to the exercise $(\mathrm{n}=15)$ or exercise + TJM group $(\mathrm{n}=20)$ and completed an exercise program. The exercise + TJM group also received MT at the talocrural, proximal, and distal tibiofibular joints in the first 3 sessions. Main Outcome Measures: Self-reported outcomes were recorded at baseline and follow-up using the Foot and Ankle Ability Measure (FAAM), the FAAM-Sport (FAAM-S) subscale, and the Ankle Joint Functional Assessment Tool (AJFAT). The side-hop test, figure-of- 8 hop test, 3 directions of the Star Excursion Balance Test, and dorsiflexion ROM were also assessed at baseline and follow-up. Results: Only the exercise + TJM group demonstrated an improvement in weightbearing dorsiflexion with the knee flexed following treatment $(P=.02)$. For all outcome measures, except ROM, subjects improved significantly at follow-up regardless of group assignment $(P \leq .01)$. Conclusions: Our data suggest that rehabilitation of patients with CAI is related to improved ROM, function, and self-reported outcomes. This provides evidence that the addition of MT to exercise may enhance improvements in ROM as compared with exercise alone. Additional research is needed to identify optimal parameters to maximize therapeutic benefit.
\end{abstract}

Keywords: functional performance, discipline area(s), manual therapy, physical therapy, ankle sprain, rehabilitation

Ankle sprains are among the most common musculoskeletal injury in the general population ${ }^{1,2}$ and up to $70 \%$ of individuals who sustain an acute ankle sprain may develop chronic ankle instability $(\mathrm{CAI}){ }^{2} \mathrm{CAI}$ is a condition characterized by repetitive giving way of the ankle, diminished self-reported function, and persistent symptoms that may impede both mechanical and functional systems of the lower-extremity. ${ }^{3}$ It has been suggested that individuals who sustain an ankle sprain may develop residual physical disabilities that impact function from activities of daily living to sport-specific tasks. ${ }^{1,2,4}$ The economic burden of ankle sprains is estimated up to $\$ 4$ billion annually, ${ }^{4}$ and the sequelae of persistent disability suggests a public health concern..$^{2,5}$ The complex sequela to CAI necessitates a multimodal, comprehensive treatment approach to address the many facets that lead to dysfunction in those with CAI.

Manual therapy directed at the ankle joint is an intervention that is part of a comprehensive treatment approach for those with $\mathrm{CAI}^{6-9}$ given that alterations in joint structure and function are likely to occur following an ankle sprain. ${ }^{10-12}$ Authors have reported an anterior displacement of the talus ${ }^{10}$ and distal fibula, ${ }^{11,12}$ a posterior displacement of the proximal fibula, ${ }^{13}$ and a loss of dorsiflexion range of motion (DFROM) following an ankle sprain. ${ }^{14}$ Manual therapy directed at the ankle joint, including

Bolton and Hale are with the Division of Physical Therapy, Shenandoah University, Winchester, VA, USA. Telemeco is with the Department of Kinesiology, College of Health Sciences, University of North Carolina at Pembroke, Pembroke, NC, USA. Bolton (Cbolton16@su.edu) is corresponding author. mobilization and high-velocity low-amplitude (HVLA) thrust manipulation techniques, has been shown to improve DFROM, reduce pain, and improve dynamic balance in individuals with CAI. ${ }^{15}$

Although the exact mechanism of manual therapy is complex and remains uncertain, it is hypothesized that manual therapy may target a centrally mediated mechanism found in those with CAI. ${ }^{16}$ Literature demonstrates the use of manual therapy as a neurophysiological agent that may affect sensory-perceptual (eg, pain); motor-behavioral (eg, balance); and pathoanatomical impairments (eg, range of motion) in those with CAI. ${ }^{3,15}$ Described in a model by Bialosky et al, ${ }^{17}$ by acting as a mechanical stimulus at the peripheral nervous system, manual therapy may affect tissue and neuromuscular responses as well as pain modulation in an individual with CAI.

There is currently a lack of literature to support 1 type of manual therapy technique, nonthrust mobilization versus thrust joint manipulation (TJM), at the ankle joint to improve outcomes in those with CAI. However, manual therapy research of the spine suggests a greater effect is seen in outcomes related to pain and disability with the addition of TJM over other forms of manual therapy. ${ }^{18,19}$ A limited number of studies have explored the combination of manual therapy and exercise compared with exercise alone on outcomes in individuals with CAI ${ }^{6-9}$ and even fewer that have explored the addition of TJM to an exercise regimen. ${ }^{7}$ Although these studies reported improvement in outcomes for those with CAI, there is lack of literature examining the effects of the addition of TJM to a therapeutic exercise regimen on functional performance. 
Therefore, the purpose of our study is to examine the effects of TJM directed at the talocrural joint and the proximal and distal tibiofibular joints in conjunction with an exercise program as compared with an exercise program alone on self-reported function, range of motion, and functional performance in those with CAI. We hypothesize that completing an exercise program in conjunction with TJM will optimize functional performance in those with CAI.

\section{Methods}

\section{Study Design}

This study was a single-blinded, randomized controlled trial (NCT03428620), which included individuals who reported CAI. Participants were recruited through a convenience sample from Shenandoah University and the surrounding community by recruitment flyers, email, and word of mouth. Participants were randomly assigned to either an exercise group $(n=15)$ or exercise + TJM group $(n=20)$. Both groups underwent 12 supervised exercise sessions across a 6-week period; the exercise + TJM group also received high-velocity low-amplitude (HVLA) thrust manipulations at the start of each of the first 3 sessions. ${ }^{20}$

\section{Randomization}

Research coordinators at the university laboratory randomly assigned eligible participants into exercise or exercise + TJM groups by simple randomization. Following group assignment, a research coordinator then counterbalanced the order in which the 3 highvelocity, low-amplitude TJMs would be administered by utilizing a Latin square. This system of counterbalancing was administered for participants in the exercise + TJM group for each of the first 3 sessions. After randomization, neither the participant nor the research coordinators were blind to group allocation; however, the examiner performing baseline and follow-up testing remained blinded to group assignment.

\section{Participants}

A convenience sample of 30 (9 males and 21 females) participants (mean age 23.7 [3.65] y; mean height 169.50 [9.50] cm; mean mass 66.48 [10.64] kg) completed the study (Table 1). For inclusion, we utilized a modified version of the International Ankle Consortium selection criteria for patients with CAI. ${ }^{21}$ Participants were required to be between the ages of 16 and 35 years, with a self-reported history of an ankle sprain resulting in reports of "giving way" or a "loose" ankle within the past 6 months and/or a decrease in functional status, as compared with the uninvolved ankle. Participants were excluded from the study if they had any lower-extremity

\section{Table 1 Participant Demographic Characteristics}

\begin{tabular}{lcc}
\hline Descriptor & $\begin{array}{c}\text { Exercise } \\
\text { Mean (SD) }\end{array}$ & $\begin{array}{c}\text { Exercise + TJM } \\
\text { Mean (SD) }\end{array}$ \\
\hline Age, y & $23.71(2.67)$ & $23.63(4.43)$ \\
Height, cm & Male: $184.15(1.80)$ & Male: $171.99(12.42)$ \\
& Female: $166.16(6.72)$ & Female: $168.77(8.53)$ \\
Mass, kg & Male: $74.55(3.86)$ & Male: $77.93(10.89)$ \\
& Female: $60.15(5.20)$ & Female: $64.21(9.28)$ \\
\hline
\end{tabular}

Abbreviation: TJM, thrust joint manipulation. injury within the past 3 months, a history of a lower-extremity fracture within 10 years, a history of vestibular dysfunction, selfreported neuromuscular diagnosis and/or mental illness, or if the participant was currently participating in another supervised rehabilitation program for the involved ankle. If the participant reported bilateral ankle sprains, the limb with the greatest self-reported dysfunction was used for analysis and treatment for both groups. ${ }^{22}$ This was verified using the Ankle Joint Functional Assessment Tool (AJFAT) in which the participants could not rate the "better ankle" as worse on any item of the AJFAT. The consort diagram is reflected in Figure 1. Before participation, all participants completed an informed consent form approved by Shenandoah University's Institutional Review Board, and the rights of the participants were protected. This study's estimated sample size was calculated using DFROM data from Cruz-Díaz et al. ${ }^{23} \mathrm{We}$ chose this outcome to be conservative, as it was the least responsive outcome measure. A sample size of $n=12$ per group was formed with this data and equated to $80 \%$ power to detect differences in the means at the level of 0.05 .

\section{Procedure}

Baseline data including functional-performance tests (figure-of-8 hop test, side-hop test, and the Star Excursion Balance Test [SEBT]); weight-bearing DFROM with the knee extended and with the knee flexed; and self-reported function (Foot and Ankle Disability Index [FAAM], FAAM-Sport, and AJFAT) were collected prior to beginning the 6-week exercise program. The same examiner administered the functional-performance tests for each participant; the examiner was blinded to both the involved limb and the group assignment. The order of limb testing and functional measures performed in the initial and final assessment was counterbalanced to ensure order had no effect on the results. Follow-up testing was completed within 1 week of completing the 6-week exercise program and was identical to baseline testing and administered by the same examiner.

Functional-Performance Testing. The figure-of- 8 hop test has been shown to have excellent reliability intraclass correlation coefficient $(\mathrm{ICC}=.95)$, to be able to detect differences between stable and unstable limbs, and to correlate with subjective reports of CAI. ${ }^{24,25}$ The participant began the test on either side of a demarcated 5-m distance. While standing on the involved ankle, the participant was instructed to "hop on 1 foot as fast as you can," twice around the figure- 8 . About 2 trials were performed with the fastest time being recorded. If the participant put the contralateral foot down, fell, or did not complete the course as outlined, they were asked to perform the trial again.

The side-hop test has been shown to have good reliability (ICC $=.84)$, is capable of detecting differences between the stable and unstable limbs, and has been shown to correlate with subjective reports of CAI. ${ }^{24,25}$ For this test, the participant stood on the involved limb on either side of 2 lines that are 30-cm apart. They were then instructed to "hop on 1 foot as fast as you can," laterally and then back to the starting position. This was counted as 2 repetitions, and 10 repetitions were performed. If the participant landed on or between the lines, this repetition was not counted, and they continued until 10 successful repetitions were completed. Participants performed 2 trials, and the fastest time was recorded.

The SEBT has been shown to have high interrater reliability (ICC $=.86-.92)$, is responsive to change, and suggested to be valid for detecting deficits in individuals with CAI. ${ }^{26-29}$ As outlined by 


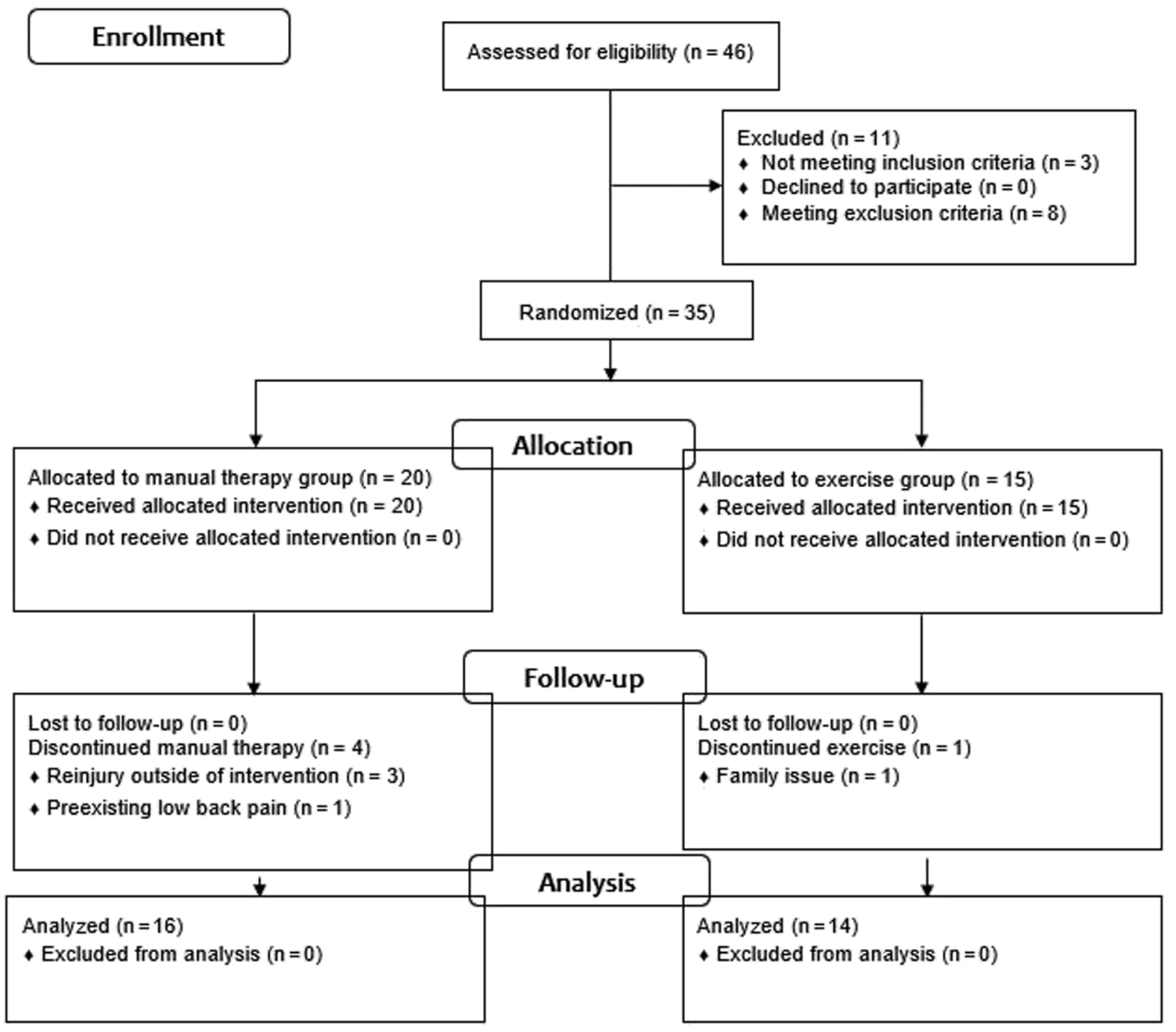

Figure 1 - CONSORT flow diagram.

Gribble et al, ${ }^{28}$ participants were asked to maintain single-limb stance, with hands on their hips, while reaching in anterior, posteromedial, and posterolateral directions. When reaching in the anterior direction, participants were positioned with the great toe just posterior to the center of the grid. When reaching in the posteromedial and posterolateral directions, participants were positioned with the heel placed just anterior to the center of the grid. A total of 6 practice reaches in each direction were allowed before recording 3 trials. ${ }^{29}$ Each participant was instructed to reach as far as possible and lightly tap their uninvolved foot on the line, then bring the foot back to the center of the grid. ${ }^{29}$ Trials were discarded and repeated if (1) the hands were removed from the hips, (2) the reaching limb was used for weight bearing, (3) the stance limb was displaced, or (4) there was a loss of balance. ${ }^{30}$ If this occurred, the participant was asked to repeat the trial. The mean of the 3recorded trials was calculated for analysis. The distance that each participant reached was also normalized to the corresponding stance leg length. ${ }^{30}$ Leg-length measurements were taken with the participant positioned in supine. The examiner measured from the inferior margin of the anterior superior iliac spine to the inferior aspect of the medial malleolus and recorded this measurement in centimeters.
Subjective Reports of Function. Measures of self-reported ankle function were completed at the start of the study and upon completion of the study. The FAAM is a 21 -item tool that has been found to be valid and reliable and is able to identify self-reported functional deficits in those with CAI ${ }^{31,32}$ Each item is scored from 4 (no difficulty) to 0 (unable to do) and has a total point value of 84 and transformed to a percentage score. ${ }^{31}$ The FAAM-S is an 8 -item tool that is a subscale of the FAAM, and has been found to detect functional deficits related to CAI in an athletic population. ${ }^{32}$ Each item is scored in the same manner as the FAAM, with a total point value of 32 points and then converted to a percentage score. ${ }^{31}$

The AJFAT is a 12-item tool that rates the participant's overall perceived level of function (eg, pain, stability, and strength) when comparing the involved limb to the uninvolved limb. ${ }^{33}$ Each item is assigned a point value from 0 (much less than other ankle) to 4 (much more than other ankle) with a possible total value of 48 points. The AJFAT has been found to be an excellent assessment tool for discriminating between stable and unstable ankles and has excellent test-retest reliability $(\mathrm{ICC}=.94) .{ }^{33}$ The AJFAT has also been shown to be responsive to changes in function following intervention. ${ }^{34}$ 
Range of Motion. Standing DFROM with the knee extended and with the knee flexed were measured with a fluid-filled bubble inclinometer (Fabrication Enterprises, White Plains, NY) using the methods described by Denegar et al. ${ }^{35}$ The use of an inclinometer has been found reliable and superior to a standard goniometer to measure ankle DFROM. ${ }^{36}$

\section{Intervention}

Exercise Protocol. Both the exercise and exercise + TJM groups performed the same exercise protocol. This exercise regimen is a modified version of the balance training program described by McKeon et al. ${ }^{27}$ Participants completed this protocol twice a week, for 6 weeks, with at least 1 day in between consecutive exercise sessions. One-on-one, supervised, exercise sessions lasted approximately 30 minutes. During each exercise session, participants were challenged to maintain a single-limb stance while performing balance activities. Participants were individually progressed on particular exercises if zero errors were observed as defined in the protocol. In addition, all participants were given a home exercise program to complete everyday of the week excluding treatment days. The participants were asked to document each time they performed the home exercise program on a log. According to the logs, participants completed the home exercise program an average of 3.0 times a week.

Manual Therapy. Participants allocated to the exercise + TJM group also received HVLA thrusts at the proximal tibiofibular, the distal tibiofibular, and talocrural joints. These HVLA TJMs were performed one time at each joint, prior to completing the exercise protocol during the first 3 treatment sessions. The order of the joints to be manipulated was randomized prior to administering. For the proximal tibiofibular joint, the participant was positioned in supine on a treatment table (Figure 2). The clinician placed a fist posterior to the fibular head and maximally flexed and externally rotated the tibia. The opposite hand applied HVLA thrust technique through the distal tibia, in an anterior to posterior direction, thus allowing the proximal fibula to translate anteriorly. For the distal tibiofibular joint, the participant was positioned in supine on a treatment table (Figure 3). A towel roll was placed parallel to the leg, under the Achilles tendon of the side to be mobilized. The distal tibia was stabilized with 1 hand while the opposite hand

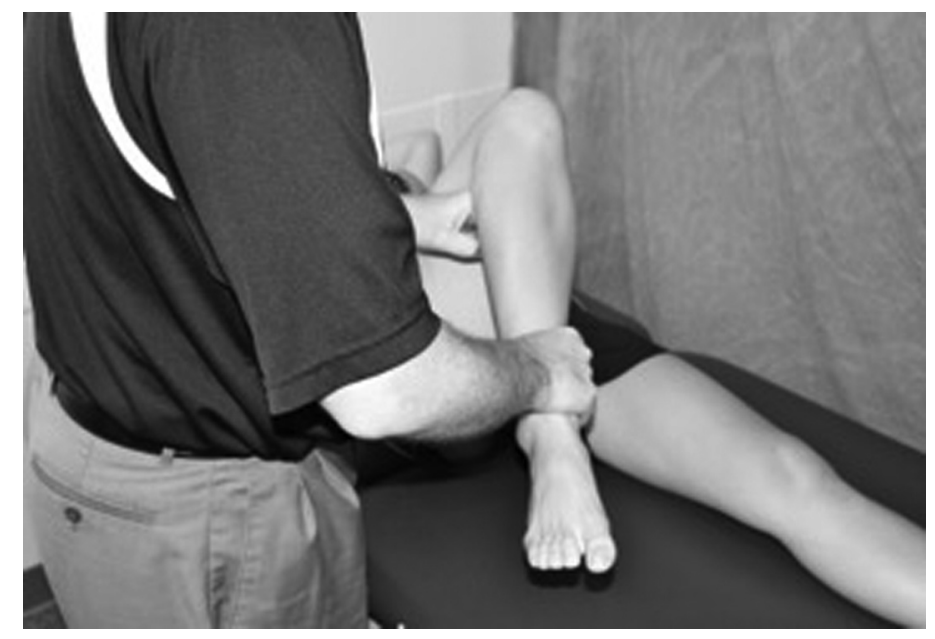

Figure 2 - Positioning for the proximal tibiofibular thrust joint manipulation. applied a HVLA thrust technique, using the thenar eminence, in an anterior to posterior direction, through the distal fibula. For the talocrural joint, the participant was positioned in supine on a treatment table (Figure 4). The limb to be manipulated was placed slightly off the end of the table. Using overlapped hands, a firm grip was applied to the ankle to be mobilized, with the medial surfaces of the fifth phalanges contacting the neck of the talus. A HVLA thrust technique was then applied in a caudal direction.

\section{Statistical Analysis}

All data analysis was performed using the IBM SPSS (version 22; IBM Corp, Armonk, NY). The alpha level was set a priori at $P<.05$. The independent variables were group (exercise + TJM, exercise) and time (baseline, follow-up). Separate $2 \times 2$ repeatedmeasures analyses of variance were used to assess changes in the FAAM, FAAM-Sport, weight-bearing DFROM with knee extended, weight-bearing DFROM with knee flexed, side-hop

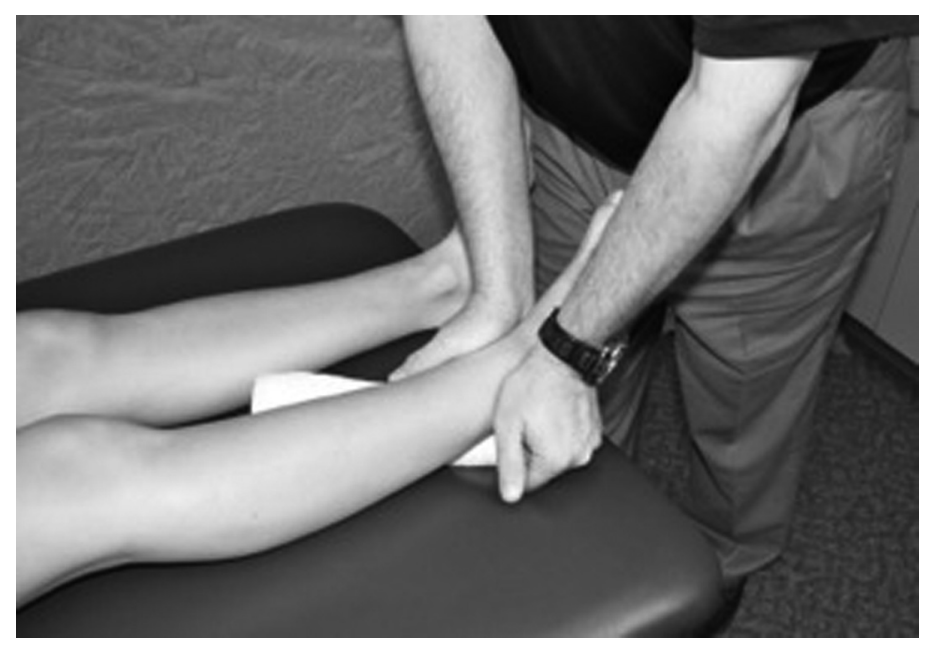

Figure 3 - Positioning for the distal tibiofibular thrust joint manipulation.

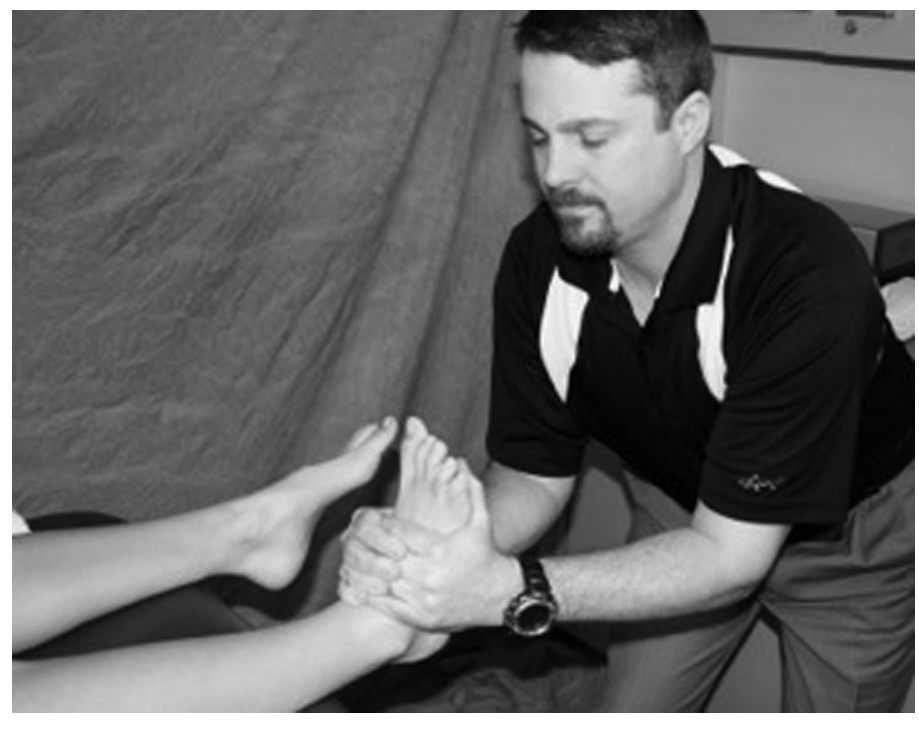

Figure 4 - Positioning for the talocrural thrust joint manipulation. 
test, and figure-of- 8 hop test, and each direction of the SEBT for each group. When a significant interaction was identified, pairwise comparisons with Sidak adjustment were used.

\section{Results}

Initially, 35 participants were randomly allocated to the exercise $(n=15)$ or exercise + TJM $(n=20)$ groups. A total of 5 participants did not complete the study. Of these, 4 were allocated to the exercise + TJM group, and 1 was in the exercise group. Of those in the exercise + TJM group, 3 withdrew due to reinjury of the involved ankle, which occurred outside of the study. The other participant withdrew due to medical conditions unrelated to the study. The participant in the exercise group withdrew due to family issues. Data from the remaining 30 participants were analyzed. Baseline and follow-up scores for each group are reflected in Tables 2 and 3.

For all of the self-reports of function and functional-performance measures, only a significant main effect of time was identified (AJFAT: $F_{1,25}=47.363, P=.000$; FAAM: $F_{1,23}=$ 7.269, $P=.01$; FAAM-S: $F_{1,23}=67.319, P=.000 ;$ SEBT $_{\text {anterior }}$ :

Table 2 Baseline and Follow-Up Measures of AJFAT, FAAM, FAAM-Sport, Side-Hop Test, Figure-of-8 Hop Test, and All 3 Directions of the SEBT Among Exercise and Exercise + TJM Groups

\begin{tabular}{|c|c|c|c|c|c|c|c|c|c|}
\hline \multirow[b]{3}{*}{ Measure } & \multicolumn{9}{|c|}{ Group } \\
\hline & \multicolumn{3}{|c|}{ Exercise } & \multicolumn{3}{|c|}{ Exercise + TJM } & \multicolumn{3}{|c|}{ Combined } \\
\hline & $\begin{array}{l}\text { Baseline } \\
\text { Mean } \\
\text { (SD) }\end{array}$ & $\begin{array}{l}\text { Follow-up } \\
\text { Mean } \\
\text { (SD) }\end{array}$ & $\begin{array}{c}\text { Change } \\
\text { score }^{\mathrm{a}} \\
(95 \% \mathrm{Cl})\end{array}$ & $\begin{array}{c}\text { Baseline } \\
\text { Mean } \\
\text { (SD) }\end{array}$ & $\begin{array}{l}\text { Follow-up } \\
\text { Mean } \\
\text { (SD) }\end{array}$ & $\begin{array}{c}\text { Change } \\
\text { score }^{a} \\
(95 \% \mathrm{Cl})\end{array}$ & $\begin{array}{c}\text { Baseline } \\
\text { Mean } \\
\text { (SD) }\end{array}$ & $\begin{array}{l}\text { Follow-up } \\
\text { Mean } \\
\text { (SD) }\end{array}$ & $\begin{array}{l}\text { Change } \\
\text { score }^{\mathrm{a}} \\
(95 \% \mathrm{Cl})\end{array}$ \\
\hline AJFAT & $\begin{array}{l}20.15 \\
(2.97)\end{array}$ & $27.61(4.37)$ & $\begin{array}{c}7.46(4.27 \text { to } \\
10.65)\end{array}$ & $\begin{array}{l}19.57 \\
(4.20)\end{array}$ & $26.14(4.80)$ & $\begin{array}{c}6.57 \text { (3.51 to } \\
9.63)\end{array}$ & $\begin{array}{l}19.85 \\
(3.60)\end{array}$ & $\begin{array}{c}26.86 \\
(4.57)^{*}\end{array}$ & $\begin{array}{c}7.00 \text { (4.94 to } \\
9.06)\end{array}$ \\
\hline FAAM, $\%$ & $\begin{array}{l}93.48 \\
(7.65)\end{array}$ & $98.02(2.50)$ & $\begin{array}{c}4.54(0.65 \text { to } \\
9.73)\end{array}$ & $\begin{array}{l}94.17 \\
(6.41)\end{array}$ & $97.28(2.94)$ & $\begin{array}{c}3.06(0.23 \text { to } \\
6.35)\end{array}$ & $\begin{array}{l}93.84 \\
(6.89)\end{array}$ & $\begin{array}{c}97.63 \\
(2.71)^{*}\end{array}$ & $\begin{array}{c}3.74(0.98 \text { to } \\
6.51)\end{array}$ \\
\hline $\begin{array}{l}\text { FAAM- } \\
\text { Sport, } \%\end{array}$ & $\begin{array}{c}82.34 \\
(10.03)\end{array}$ & $93.15(9.32)$ & $\begin{array}{c}10.81(7.22 \text { to } \\
14.40)\end{array}$ & $\begin{array}{c}77.47 \\
(11.51)\end{array}$ & $89.96(8.83)$ & $\begin{array}{c}12.48(7.53 \text { to } \\
17.43)\end{array}$ & $\begin{array}{c}79.81 \\
(10.89)\end{array}$ & $\begin{array}{c}91.49 \\
(9.03)^{*}\end{array}$ & $\begin{array}{c}11.70(8.79 \text { to } \\
14.57)\end{array}$ \\
\hline $\begin{array}{l}\text { Side-hop } \\
\text { test, s }\end{array}$ & $\begin{array}{c}6.29 \\
(1.41)\end{array}$ & $5.40(0.84)$ & $\begin{array}{c}0.89(0.30 \text { to } \\
1.47)\end{array}$ & $\begin{array}{c}6.75 \\
(2.61)\end{array}$ & $6.00(2.16)$ & $\begin{array}{c}0.75(0.05 \text { to } \\
1.46)\end{array}$ & $\begin{array}{c}6.54 \\
(2.12)\end{array}$ & $\begin{array}{c}5.72 \\
(1.68)^{*}\end{array}$ & $\begin{array}{c}0.82(0.38 \text { to } \\
1.25)\end{array}$ \\
\hline $\begin{array}{l}\text { Figure-of- } 8 \\
\text { hop test, } \mathrm{s}\end{array}$ & $\begin{array}{l}14.21 \\
(1.47)\end{array}$ & $13.43(1.31)$ & $\begin{array}{c}0.78(0.17 \text { to } \\
1.39)\end{array}$ & $\begin{array}{l}14.89 \\
(3.55)\end{array}$ & $13.21(2.76)$ & $\begin{array}{c}1.68(0.58 \text { to } \\
2.76)\end{array}$ & $\begin{array}{l}14.57 \\
(2.76)\end{array}$ & $\begin{array}{l}13.31 \\
(2.17)^{*}\end{array}$ & $\begin{array}{c}1.26(0.62 \text { to } \\
1.89)\end{array}$ \\
\hline $\begin{array}{l}\text { SEBT-A, } \\
\% \text { LL }\end{array}$ & $\begin{array}{l}75.87 \\
(9.23)\end{array}$ & $80.01(8.20)$ & $\begin{array}{c}4.13(0.33 \text { to } \\
7.93)\end{array}$ & $\begin{array}{l}70.91 \\
(7.91)\end{array}$ & $74.84(6.74)$ & $\begin{array}{c}3.94(2.32 \text { to } \\
5.55)\end{array}$ & $\begin{array}{l}73.22 \\
(8.77)\end{array}$ & $\begin{array}{c}77.25 \\
(7.78)^{*}\end{array}$ & $\begin{array}{c}4.03(2.19 \text { to } \\
5.87)\end{array}$ \\
\hline $\begin{array}{l}\text { SEBT-PM, } \\
\% \text { LL }\end{array}$ & $\begin{array}{l}88.81 \\
(8.73)\end{array}$ & $94.34(8.91)$ & $\begin{array}{c}5.53(3.61 \text { to } \\
7.46)\end{array}$ & $\begin{array}{l}85.51 \\
(8.94)\end{array}$ & $88.34(7.38)$ & $\begin{array}{c}2.84(0.63 \text { to } \\
5.04)\end{array}$ & $\begin{array}{l}87.05 \\
(8.85)\end{array}$ & $\begin{array}{c}91.14 \\
(8.55)^{*}\end{array}$ & $\begin{array}{c}4.10(2.62 \text { to } \\
5.58)\end{array}$ \\
\hline $\begin{array}{l}\text { SEBT-PL, } \\
\% \text { LL }\end{array}$ & $\begin{array}{c}80.87 \\
(11.15)\end{array}$ & $87.35(9.12)$ & $\begin{array}{c}6.49(2.60 \text { to } \\
10.38)\end{array}$ & $\begin{array}{l}78.52 \\
(9.31)\end{array}$ & $82.99(8.03)$ & $\begin{array}{c}4.47 \text { (1.62 to } \\
7.33)\end{array}$ & $\begin{array}{l}79.61 \\
(10.10)\end{array}$ & $\begin{array}{c}85.03 \\
(8.69)^{*}\end{array}$ & $\begin{array}{c}5.41(3.17 \text { to } \\
7.66)\end{array}$ \\
\hline
\end{tabular}

Abbreviations: \%LL, percent of leg length; A, anterior; AJFAT, ankle joint functional assessment tool; CI, confidence interval; FAAM, foot and ankle ability measure; FAAM-Sport, foot and ankle ability measure sport subscale; PL, posterolateral; PM, posteromedial; SEBT, star excursion balance test; TJM, thrust joint manipulation. ${ }^{a}$ Change scores represented as a positive reflect an improvement. A negative change score reflects a decline in function.

*Statistically significant difference between baseline and follow-up $(P<.05)$.

Table 3 Baseline and Follow-Up Passive Weight-Bearing Dorsiflexion Range of Motion Measurements Among Exercise and Exercise + TJM Groups

\begin{tabular}{|c|c|c|c|c|c|c|c|c|c|}
\hline \multirow[b]{3}{*}{ Measure } & \multicolumn{9}{|c|}{ Group } \\
\hline & \multicolumn{3}{|c|}{ Exercise } & \multicolumn{3}{|c|}{ Exercise + TJM } & \multicolumn{3}{|c|}{ Combined } \\
\hline & $\begin{array}{c}\text { Baseline } \\
\text { Mean } \\
\text { (SD) }\end{array}$ & $\begin{array}{l}\text { Follow- } \\
\text { up } \\
\text { Mean } \\
\text { (SD) }\end{array}$ & $\begin{array}{c}\text { Change } \\
\text { Score }^{\mathrm{a}} \\
(95 \% \mathrm{Cl})\end{array}$ & $\begin{array}{c}\text { Baseline } \\
\text { Mean (SD) }\end{array}$ & $\begin{array}{l}\text { Follow-up } \\
\text { Mean (SD) }\end{array}$ & $\begin{array}{c}\text { Change } \\
\text { Score }^{\mathrm{a}} \\
(95 \% \mathrm{Cl})\end{array}$ & $\begin{array}{c}\text { Baseline } \\
\text { Mean } \\
\text { (SD) }\end{array}$ & $\begin{array}{l}\text { Follow-up } \\
\text { Mean (SD) }\end{array}$ & $\begin{array}{c}\text { Change } \\
\text { Score } \\
(95 \% \mathrm{Cl})\end{array}$ \\
\hline $\begin{array}{l}\text { DFROM knee } \\
\text { extended }\end{array}$ & $\begin{array}{l}19.07 \\
(5.36)\end{array}$ & $\begin{array}{l}20.36 \\
(4.48)\end{array}$ & $\begin{array}{c}1.29(-2.38 \\
\text { to } 4.95)\end{array}$ & $18.13(7.11)$ & $19.25(6.25)$ & $\begin{array}{c}1.13(-2.79 \\
\text { to } 5.04)\end{array}$ & $\begin{array}{l}18.57 \\
(6.26)\end{array}$ & $19.77(5.43)$ & $\begin{array}{c}1.20(-1.33 \\
\text { to } 3.73)\end{array}$ \\
\hline $\begin{array}{l}\text { DFROM knee } \\
\text { flexion }\end{array}$ & $\begin{array}{l}26.29 \\
(2.97)\end{array}$ & $\begin{array}{l}24.57 \\
(3.80)\end{array}$ & $\begin{array}{c}-1.71(-3.95 \\
\text { to } 0.52)\end{array}$ & $19.81(5.91)$ & $23.50(5.91)^{*}$ & $\begin{array}{c}3.69(-0.15 \\
\text { to } 7.53)\end{array}$ & $\begin{array}{l}22.83 \\
(6.13)\end{array}$ & $24.00(4.98)$ & $\begin{array}{c}1.17(-1.23 \\
\text { to } 3.56)\end{array}$ \\
\hline
\end{tabular}

Abbreviations: CI, confidence interval; DFROM, dorsiflexion range of motion; TJM, thrust joint manipulation.

${ }^{a}$ Change scores represented as a positive reflect an improvement. A negative change score reflects a decline in function.

*Statistically significant difference between baseline and follow-up $(P<.05)$. 
$F_{1,28}=19.420, P<.0005 ; \mathrm{SEBT}_{\text {posteromedial }}: F_{1,28}=36.440, P<$ .0005 ; SEBT $_{\text {posterolateral }}: F_{1,28}=24.599, P<.0005$; side-hop test: $F_{1,28}=14.197, \quad P=.001$; figure-of-8 hop test: $F_{1,28}=16.184$, $P<.0005)$. For each of these measures, participants reported and demonstrated improvements at follow-up, when compared with baseline, regardless of treatment group (see Table 2 for a summary of change in each group).

There was a significant interaction between group and time for DFROM with the knee flexed $\left(F_{1,28}=6.261, P=.02\right)$, suggesting the effect of time depended on group assignment. Post hoc testing was unable to identify the significant difference. However, the significant interaction and the point estimates of the mean difference for each group suggest that only the exercise + TJM group demonstrated improvements across time (see Table 3 for summary of change in each group). When analyzing measurements of DFROM with the knee extended, we did not identify any significant main effects (time: $F_{1,28}=0.910, P=.35$; group: $F_{1,28}=$ $0.337, P=.56)$ nor a significant interaction between time and group $\left(F_{1,28}=0.004, P=.95\right)$. This suggests that neither time nor group had an effect on DFROM with the knee extended (see Table 3 for summary of change in each group).

\section{Discussion}

The purpose of this study was to compare the combined effects of TJM and therapeutic exercise on function to the effects of therapeutic exercise alone in participants reporting CAI. Our results suggest that the addition of TJM improves DFROM in those with CAI compared with therapeutic exercise alone. Although statistically significant improvements were measured in self-reported function and functional, no group differences were noted.

The statistically significant improvements we identified likely have clinical significance as well. Specifically, our participants' baseline scores for the AJFAT, FAAM-S, SEBT-PM, and side-hop test were suggestive of CAI given cut-off scores published in the literature (AJFAT: $\geq 26$; FAAM-S: 80\%; SEBT-PM: 91\%; side-hop test: $12.88 \mathrm{~s}) .^{21,33,37}$ Upon follow-up testing, participants' selfreported function and performance exceeded these cut-off scores and therefore suggest the resolution of CAI. To compare cut-off scores on the side-hop test, the cut-off score provided by Linens et $\mathrm{al}^{37}$ was reduced by $50 \%$; this is due to a difference in the operational definition of a repetition for the side-hop test. Changes in function and functional performance in our study may be attributed to the therapeutic exercise regimen given that the regimen was common to both groups, both groups improved, and previous literature reflects that a therapeutic exercise regimen is associated with improvements in self-reported function and functional performance. $22,27,38,39$

Although therapeutic exercise is shown to be effective in improving self-reported function and functional performance in those with CAI, the effects of adding manual therapy to an exercise program is less clear. Studies that examined the combined effects of manual therapy with therapeutic exercise have mixed findings. ${ }^{6-9}$ Burcal et $\mathrm{al}^{9}$ demonstrated that therapeutic exercise combined with sensory-targeted-rehabilitation strategies, including ankle mobilizations, was no more effective than balance training alone. While Burcal et $\mathrm{al}^{9}$ report results favored the multimodal approach, no significant differences were identified between groups. In contrast, some studies report that the addition of manual therapy, including TJM, leads to improved outcomes in those with CAI compared with exercise alone. ${ }^{6-8}$
Although the addition of TJM did not appear to result in greater improvement in self-reported function and functionalperformance compared with exercise alone in our study, we did find that the addition of TJM led to greater improvements in DFROM. With the knee flexed, the TJM group demonstrated $3.69^{\circ}$ increase in DFROM following the 6-week intervention. To our knowledge, there is no reported minimal clinically important difference in weight-bearing DFROM with the knee flexed using the methods described by Denegar et al. ${ }^{35}$ To compare our findings, Denegar et $\mathrm{al}^{35}$ reported a difference of $2.9^{\circ}$ in the standing bent knee DFROM measurement between injured and uninjured limbs. ${ }^{35}$ We may deduce from the findings by Denegar et $\mathrm{al}^{35}$ that the difference of $3.69^{\circ}$ found in our study may be clinically relevant.

The effects of TJM on DFROM in those with CAI reported in the literature are inconsistent. Similar to our study, Marrón-Gómez et $\mathrm{al}^{40}$ found significant improvement in weight-bearing DFROM with the knee flexed following manual therapy interventions. But, Beazell et $\mathrm{al}^{41}$ found no significant changes to DFROM following TJM. It is difficult to compare findings due to the variability in parameters across studies. The variability in manual therapy techniques and dosage in the literature supports the need to determine ideal parameters that will lead to improvements in DFROM. Although we cannot state the exact reason as to why TJM improved DFROM, a model by Bialosky et $\mathrm{al}^{42}$ suggests there may be either biomechanical or neurophysiological effects of manual therapy including TJM. Although our study found improvements in DFROM with the addition of TJM and improvements in self-reported function and functional performance in both groups, we must discuss the potential limitations that may impacted our findings. The small sample size of the study, the lack of a short-term reassessment, and the manual therapy parameters we selected may have influenced our findings. A larger sample size may have yielded group differences that were statistically significant. In addition, the TJM was performed at the first 3 sessions out of a total of 12 sessions, and the outcomes were assessed after the 12 th visit. It is possible that the investigators did not capture a short-term benefit of the addition of TJM earlier in the 6-week intervention that has been seen in the literature. ${ }^{40}$ Finally, there is still a lack of literature to support optimal parameters and dosage for manual therapy. Thus, the addition of TJM at the first 3 sessions may not have been the optimal parameter for benefit. This idea is outside the scope of this study, however, and warrants further research to determine ideal parameters of manual therapy at the ankle joint.

\section{Conclusions}

To our knowledge, this study is the first of its kind to demonstrate the benefits of combining TJM and therapeutic exercises on range of motion, self-reported function, and functional performance. These findings reflect current practice that therapeutic exercise improves self-reported function and functional performance. In addition, it highlights the importance of a multimodal approach to the treatment of CAI, specifically that the addition of TJM to a therapeutic exercise regimen has the greatest benefit on weightbearing DFROM in those with CAI.

\section{Acknowledgments}

The authors have no financial affiliation (including research funding) or involvement with any commercial organization that has a direct financial 
interest in any matter included in this manuscript. They have no conflict of interest (ie, personal associations or involvement as a director, officer, or expert witness).

\section{References}

1. Waterman BR, Owens BD, Davey S, Zacchilli MA, Belmont PJ Jr. The epidemiology of ankle sprains in the United States. J Bone Joint Surg Am. 2010;92(13):2279-2284. PubMed ID: 20926721 doi:10. 2106/JBJS.I.01537

2. Gribble PA, Bleakley CM, Caulfield BM, et al. Evidence review for the 2016 International Ankle Consortium consensus statement on the prevalence, impact and long-term consequences of lateral ankle sprains. Br J Sports Med. 2016;50(24):1496-1505. PubMed ID: 27259753 doi:10.1136/bjsports-2016-096189

3. Hertel J, Corbett RO. An updated model of chronic ankle instability. J Athl Train. 2019;54(6):572-588. PubMed ID: 31162943 doi:10. 4085/1062-6050-344-18

4. Gerber JP, Williams GN, Scoville CR, Arciero RA, Taylor DC. Persistent disability associated with ankle sprains: a prospective examination of an athletic population. Foot Ankle Int. 1998; 19(10):653-660. PubMed ID: 9801078 doi:10.1177/10711007980 1901002

5. Gribble PA, Bleakley CM, Caulfield BM, et al. 2016 consensus statement of the International Ankle Consortium: prevalence, impact and long-term consequences of lateral ankle sprains. Br J Sports Med. 2016;50(24):1493-1495. PubMed ID: 27259750 doi:10.1136/ bjsports-2016-096188

6. Plaza-Manzano G, Vergara-Vila M, Val-Otero S, et al. Manual therapy in joint and nerve structures combined with exercises in the treatment of recurrent ankle sprains: a randomized, controlled trial. Man Ther. 2016;26:141-149. PubMed ID: 27598553 doi:10. 1016/j.math.2016.08.006

7. Lubbe D, Lakhani E, Brantingham JW, et al. Manipulative therapy and rehabilitation for recurrent ankle sprain with functional instability: a short-term, assessor-blind, parallel-group randomized trial. J Manipulative Physiol Ther. 2015;38(1):22-34. PubMed ID: 25457977 doi:10.1016/j.jmpt.2014.10.001

8. Shih Y-F, Yu H-T, Chen W-Y, Liao K-K, Lin H-C, Yang Y-R. The effect of additional joint mobilization on neuromuscular performance in individuals with functional ankle instability. Phys Ther Sport. 2018;30:22-28. PubMed ID: 29310055 doi:10.1016/j.ptsp.2017. 12.001

9. Burcal CJ, Trier AY, Wikstrom EA. Balance training versus balance training with STARS in patients with chronic ankle instability: a randomized controlled trial. J Sport Rehabil. 2017;26(5):347-357. PubMed ID: 27632839 doi:10.1123/jsr.2016-0018

10. Wikstrom EA, Hubbard TJ. Talar positional fault in persons with chronic ankle instability. Arch Phys Med Rehabil. 2010;91(8):12671271. PubMed ID: 20684909 doi:10.1016/j.apmr.2010.04.022

11. Hubbard TJ, Hertel J. Anterior positional fault of the fibula after subacute lateral ankle sprains. Man Ther. 2008;13(1):63-67. PubMed ID: 17188923 doi:10.1016/j.math.2006.09.008

12. Hubbard TJ, Hertel J, Sherbondy P. Fibular position in individuals with self-reported chronic ankle instability. J Orthop Sports Phys Ther. 2006;36(1):3-9. PubMed ID: 16494068 doi:10.2519/jospt. 2006.36.1.3

13. Grindstaff TL, Beazell JR, Sauer LD, Magrum EM, Ingersoll CD, Hertel J. Immediate effects of a tibiofibular joint manipulation on lower extremity H-reflex measurements in individuals with chronic ankle instability. J Electromyogr Kinesiol. 2011;21(4):652-658. PubMed ID: 21546263 doi:10.1016/j.jelekin.2011.03.011

14. Hoch MC, Staton GS, Medina McKeon JM, Mattacola CG, McKeon PO. Dorsiflexion and dynamic postural control deficits are present in those with chronic ankle instability. J Sci Med Sport. 2012;15(6): 574-579. PubMed ID: 22575498 doi:10.1016/j.jsams.2012.02.009

15. Weerasekara I, Osmotherly P, Snodgrass S, Marquez J, de Zoete R, Rivett DA. Clinical benefits of joint mobilization on ankle sprains: a systematic review and meta-analysis. Arch Phys Med Rehabil. 2018;99(7):1395-1412.e5. PubMed ID: 28882509 doi:10.1016/j. apmr.2017.07.019

16. Evans T, Hertel J, Sebastianelli W. Bilateral deficits in postural control following lateral ankle sprain. Foot Ankle Int. 2004;25(11): 833-839. PubMed ID: 15574245 doi:10.1177/107110070402501114

17. Bialosky JE, Bishop MD, Price DD, Robinson ME, George SZ. The mechanisms of manual therapy in the treatment of musculoskeletal pain: a comprehensive model. Man Ther. 2009;14(5):531-538. PubMed ID: 19027342 doi:10.1016/j.math.2008.09.001

18. Coulter ID, Crawford C, Vernon H, et al. Manipulation and mobilization for treating chronic nonspecific neck pain: a systematic review and meta-analysis for an appropriateness panel. Pain Physician. 2019;22(2):E55-E70. PubMed ID: 30921975

19. Gross A, Miller J, D'sylva J, et al. Manipulation or mobilisation for neck pain: a Cochrane review. Man Ther. 2010;15(4):315-333. PubMed ID: 20510644 doi:10.1016/j.math.2010.04.002

20. Green T, Refshauge K, Crosbie J, Adams R. A randomized controlled trial of a passive accessory joint mobilization on acute ankle inversion sprains. Phys Ther. 2001;81(4):984-994. PubMed ID: 11276181 doi:10.1093/ptj/81.4.984

21. Gribble PA, Delahunt E, Bleakley C, et al. Selection criteria for patients with chronic ankle instability in controlled research: a position statement of the International Ankle Consortium. J Orthop Sports Phys Ther. 2013;43(8):585-591. PubMed ID: 23902805 doi:10.2519/jospt.2013.0303

22. Hale SA, Hertel J, Olmsted-Kramer LC. The effect of a 4-week comprehensive rehabilitation program on postural control and lower extremity function in individuals with chronic ankle instability. J Orthop Sports Phys Ther. 2007;37(6):303-311. PubMed ID: 17612356 doi:10.2519/jospt.2007.2322

23. Cruz-Díaz D, Lomas Vega R, Osuna-Pérez MC, Hita-Contreras F, Martínez-Amat A. Effects of joint mobilization on chronic ankle instability: a randomized controlled trial. Disabil Rehabil. 2015; 37(7):601-610. doi:10.3109/09638288.2014.935877

24. Docherty CL, Arnold BL, Gansneder BM, Hurwitz S, Gieck J. Functional-performance deficits in volunteers with functional ankle instability. J Athl Train. 2005;40(1):30-34. PubMed ID: 15902321

25. Caffrey E, Docherty CL, Schrader J, Klossner J. The ability of 4 single-limb hopping tests to detect functional performance deficits in individuals with functional ankle instability. J Orthop Sports Phys Ther. 2009;39(11):799-806. PubMed ID: 19881005 doi:10.2519/ jospt.2009.3042

26. Olmsted LC, Carcia CR, Hertel J, Shultz SJ. Efficacy of the star excursion balance tests in detecting reach deficits in subjects with chronic ankle instability. $J$ Athl Train. 2002;37(4):501-506. PubMed ID: 12937574

27. McKeon PO, Ingersoll CD, Kerrigan DC, Saliba E, Bennett BC, Hertel J. Balance training improves function and postural control in those with chronic ankle instability. Med Sci Sports Exerc. 2008; 40(10):1810-1819. PubMed ID: 18799992 doi:10.1249/MSS.0b013 e31817e0f92 
28. Gribble PA, Kelly SE, Refshauge KM, Hiller CE. Interrater reliability of the star excursion balance test. J Athl Train. 2013;48(5):621-626. PubMed ID: 24067151 doi:10.4085/1062-6050-48.3.03

29. Hertel J, Miller S, Denegar CR. Intratester and intertester reliability during the star excursion balance tests. J Sports Rehabil. 2000;9: 104-116. doi:10.1123/jsr.9.2.104

30. Gribble PA, Hertel J. Considerations for normalizing measures of the star excursion balance test. Meas Phys Educ Exerc Sci. 2003;7(2): 89-100. doi:10.1207/S15327841MPEE0702_3

31. Martin RL, Irrgang JJ, Burdett RG, Conti SF, Van Swearingen JM. Evidence of validity for the foot and ankle ability measure (FAAM). Foot Ankle Int. 2005;26(11):968-983. PubMed ID: 16309613 doi:10. 1177/107110070502601113

32. Carcia CR, Martin RL, Drouin JM. Validity of the foot and ankle ability measure in athletes with chronic ankle instability. J Athl Train. 2008;43(2):179-183. PubMed ID: 18345343 doi:10.4085/10626050-43.2.179

33. Ross SE, Guskiewicz KM, Gross MT, Yu B. Assessment tools for identifying functional limitations associated with functional ankle instability. J Athl Train. 2008;43(1):44-50. PubMed ID: 18335012 doi:10.4085/1062-6050-43.1.44

34. Rozzi SL, Lephart SM, Sterner R, Kuligowski L. Balance training for persons with functionally unstable ankles. J Orthop Sports Phys Ther. 1999;29(8):478-486. PubMed ID: 10444738 doi:10.2519/jospt. 1999.29.8.478

35. Denegar CR, Hertel J, Fonseca J. The effect of lateral ankle sprain on dorsiflexion range of motion, posterior talar glide, and joint laxity. J Orthop Sports Phys Ther. 2002;32(4):166-173. PubMed ID: 11949665 doi:10.2519/jospt.2002.32.4.166
36. Konor MM, Morton S, Eckerson JM, Grindstaff TL. Reliability of three measures of ankle dorsiflexion range of motion. Int $J$ Sports Phys Ther. 2012;7(3):279-287. PubMed ID: 22666642

37. Linens SW, Ross SE, Arnold BL, Gayle R, Pidcoe P. Posturalstability tests that identify individuals with chronic ankle instability. $J$ Athl Train. 2014;49(1):15-23. PubMed ID: 24377958 doi:10.4085/ 1062-6050-48.6.09

38. Hale SA, Fergus A, Axmacher R, Kiser K. Bilateral improvements in lower extremity function after unilateral balance training in individuals with chronic ankle instability. $J$ Athl Train. 2014;49(2):181-191. PubMed ID: 24568231 doi:10.4085/1062-6050-49.2.06

39. Wright C, Linens S, Cain M. A randomized controlled trial comparing rehabilitation efficacy in chronic 1 ankle instability. J Sport Rehabil. 2017;26(4):238-249. PubMed ID: 27632874 doi:10.1123/jsr.20150189

40. Marrón-Gómez D, Rodríguez-Fernández ÁL, Martín-Urrialde JA. The effect of two mobilization techniques on dorsiflexion in people with chronic ankle instability. Phys Ther Sport. 2015;16(1):10-15. doi:10.1016/j.ptsp.2014.02.001

41. Beazell JR, Grindstaff TL, Sauer LD, Magrum EM, Ingersoll CD, Hertel J. Effects of a proximal or distal tibiofibular joint manipulation on ankle range of motion and functional outcomes in individuals with chronic ankle instability. J Orthop Sports Phys Ther. 2012;42(2):125-134. PubMed ID: 22333567 doi:10.2519/jospt. 2012.3729

42. Bialosky JE, Beneciuk JM, Bishop MD, et al. Unraveling the mechanisms of manual therapy: modeling an approach. J Orthop Sports Phys Ther. 2018;48(1):8-18. PubMed ID: 29034802 doi:10. 2519/jospt.2018.7476 